\title{
Structure Design of Pure Electric Car
}

\author{
Xiao-Yun Li ${ }^{1}$, Yi-Jui Chiu ${ }^{1, a,{ }^{*}}$, Ke-Ke Sun ${ }^{2, ~ b}$, Sheng-Bo Li ${ }^{1 \mathrm{c}}$ and Ze-Liang Sun ${ }^{1}$ \\ ${ }^{1}$ School of Mechanical and Automotive Engineering, Xiamen University of Technology, No. 600, \\ Ligong Rd, Xiamen, 361024, Fujian Province, China. \\ ${ }^{2}$ School of Design Arts and Fashion Design, Xiamen University of Technology, No. 600, Ligong Rd, \\ Xiamen, 361024, Fujian Province, China. \\ achiuyijui@xmut.edu.cn, bsunkeke@xmut.edu.cn, hit4057@xmut.edu.cn
}

Keywords: Electric car; Finite element model; Strength analysis; Stiffness analysis; Modal analysis

\begin{abstract}
This paper used SolidWorks to design pure electric car structure, and interfaced into the ANSYS through the graphical data conversion. The finite element model of the vehicle is generated by grid division. The finite element analysis of the vehicle body is carried out. The strength and stiffness characteristics of the vehicle body under different working conditions are calculated in the static analysis. The frequency of the vehicle body is calculated by modal analysis.
\end{abstract}

\section{Introduction}

Pure electric vehicles are considered to be the future of the car. It has the advantage as follow: low emissions, less pollution, relatively simple structure and light weight. The researches are in this field, such as Rinspeed company[1] published a small electric car, which is called "eXasis". The car body is made of a transparent design, and used frame body and body structure of high tech plastic panel. Wang et. al. [2] designed the layout of car body. Lei and Xiao [3] carried out the conceptual design and topology optimization design of pure electric vehicles under many working conditions. After the model is built, $40 \%$ of the head shell is subjected to finite element analysis. Finally, the deformation head is optimized to achieve the crashworthiness of the vehicle body and the lightweight is designed. Botkin [4] adopted the topology optimization method to achieve the optimization goal of automobile structural design by re-distributing the material in the structure. Nagesh [5] et. al. explored the NVH performance of pure electric vehicle. It includes noise, vibration, and harshness. Zhu et.al. [6] explored the dynamic behavior of three distinctive types of automobile. They used ANSYS to simulate the modal analysis of the vehicle frameworks and introduced the vibration and the resonance behavior of localizations.

The intention of this paper is to design a pure electric car according to the dynamic parameters of a predetermined location. On the basis of meeting stiffness and strength requirements, lightweight design is achieved, and vibration analysis is performed.

\section{Theories Analysis}

In this paper, the VonMises criterion is used to determine whether the body strength conforms to the strength requirement. Whether the maximum stress is taken by the car body or whether it is within the allowable stress range of the material. Bending rigidity of car body is

$$
K_{B}=W / D
$$

where $\mathrm{W}$ is the total load applied, $\mathrm{D}$ is the maximum vertical deflection.

And, torsional rigidity of car body is

$$
K_{T}=F L / \theta
$$

where $\mathrm{F}$ is the vertical load applied to the front suspension, $\mathrm{L}$ is the pure electric car body wheelbase. $\theta$ is the relative rotation angle of car body. 
Because the structure of body structure of pure electric car was very complex, we should simplify the structure first. This paper exports the equations of the system.

$[M]\{\ddot{X}\}+[K]\{X\}=0$

Defined the position vector $\{\mathrm{X}\}$ as $[\Delta]\{\mathrm{u}\}$, where $[\Delta]$ was the modal matrix of the system. Eq. (3) could be changed as follow:

$$
[I]\{\ddot{u}\}+[A]\{u\}=0
$$

In which:

$$
\begin{gathered}
{[\Delta]^{T}[M][\Delta]=[I]=\left[\begin{array}{cccc}
1 & 0 & \cdots & 0 \\
0 & 1 & \cdots & \vdots \\
\vdots & 0 & \ddots & 0 \\
0 & 0 & 0 & 1
\end{array}\right]} \\
{[\Delta]^{T}[K][\Delta]=[A]=\left[\begin{array}{cccc}
\bar{\omega}_{1}^{2} & 0 & \cdots & 0 \\
0 & \bar{\omega}_{2}^{2} & \cdots & \vdots \\
\vdots & 0 & \ddots & 0 \\
0 & \cdots & 0 & {\frac{\omega}{\omega_{n}}}^{2}
\end{array}\right]}
\end{gathered}
$$

The natural frequency of the mistuned system was expressed as follow:

$$
\overline{\omega_{n}}=\frac{\omega_{n}}{\sqrt{\frac{E I}{\rho A L^{4}}}}, n=1,2,3 \ldots \ldots
$$

\section{Finite Element Modeling}

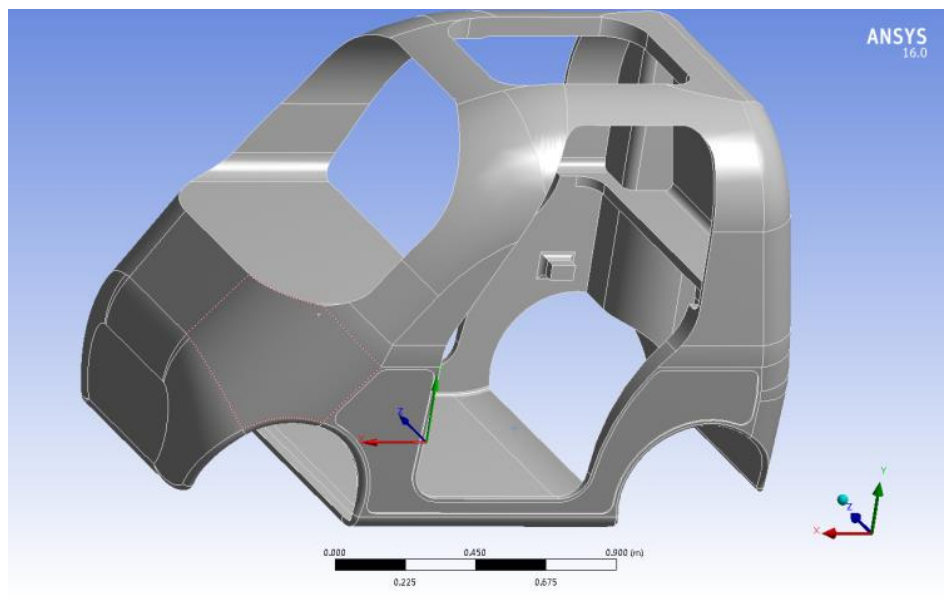

Figure 1. Model import

This paper imported the 3D geometry model built in SolidWorks into ANSYS, as shown in Fig. 1. The pure electric car designed into account the lightweight factors in this paper takes. Table 1 shows the design parameters of pure electric car. The aluminum alloy is taken as the material for the body structure, and the specific parameters are shown in the following table 2. After the mesh is divided, the finite element model is shown in Figure 2. The model contains 114126 elements and 185284 nodes. The element types are choice 3D hexahedral solid elements. 
Table 1 The design parameters of pure electric car

\begin{tabular}{cccc}
\hline Length $\leq 2500 \mathrm{~mm}$ & Width $\leq 1200 \mathrm{~mm}$ & High $\leq 1500 \mathrm{~mm}$ & Vehicle weight $\leq 300 \mathrm{~kg}$ \\
\hline Carrying capacity $\leq 150 \mathrm{~kg}$ & Maximum gradient $\geq 20^{\circ}$ & Average speed $=40 \mathrm{~km} / \mathrm{h}$ & Windward area $\approx 1.1 \mathrm{~m}^{2}$ \\
\hline
\end{tabular}

Table 2. Car body material parameter

\begin{tabular}{ccccc}
\hline & Density & Young Modulus & Shear Modulus & Poisson ratio \\
Aluminium & $2.77 \mathrm{~g} / \mathrm{cm}^{3}$ & $7.1 \times 10^{10} \mathrm{~Pa}$ & $2.67 \times 10^{10} \mathrm{~Pa}$ & 0.33 \\
\hline
\end{tabular}

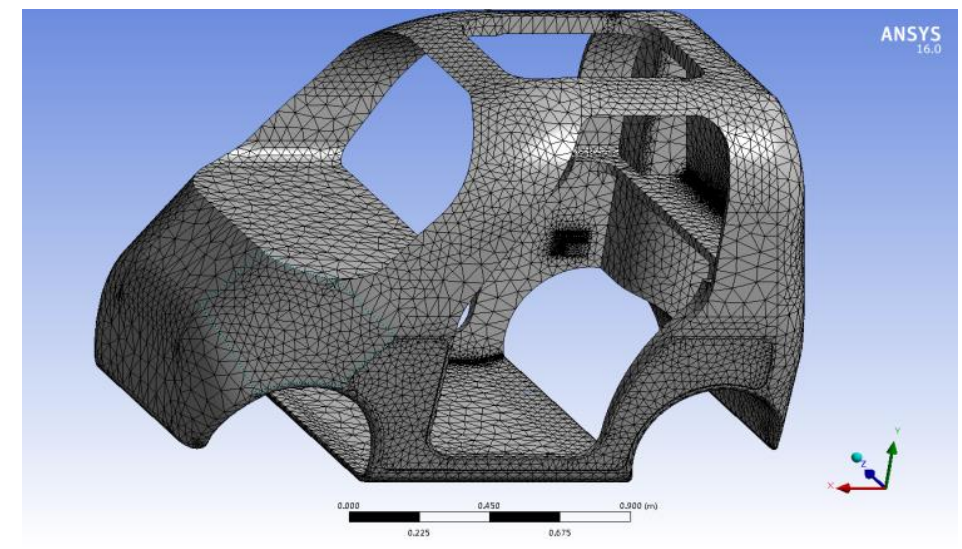

Figure 2. Mesh divides

\section{Static Analysis}

Loading mode of automobile body in bending condition is shown in Fig.3. The boundary condition is the degree of freedom of all supporting seats to restrain the $\mathrm{X}, \mathrm{Y}$ and $\mathrm{Z}$ directions before and after the constraint. The load condition is given $4000 \mathrm{~N}$ concentrated force on the center of the seat.

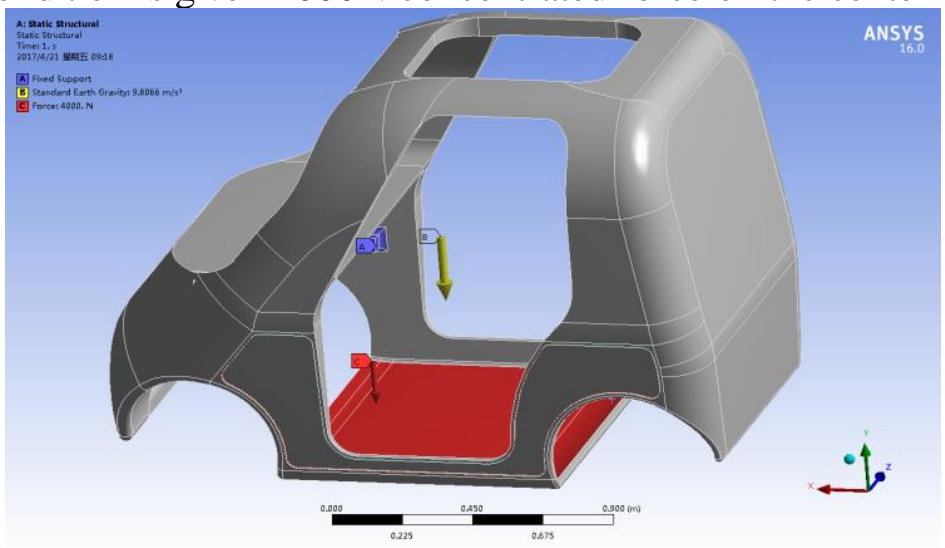

Figure 3. Bending load constraints are applied

By solving the ANSYS processor, the deformation of strain and stress under bending conditions can be obtained, as shown in figures 4(a) and 4(b). 


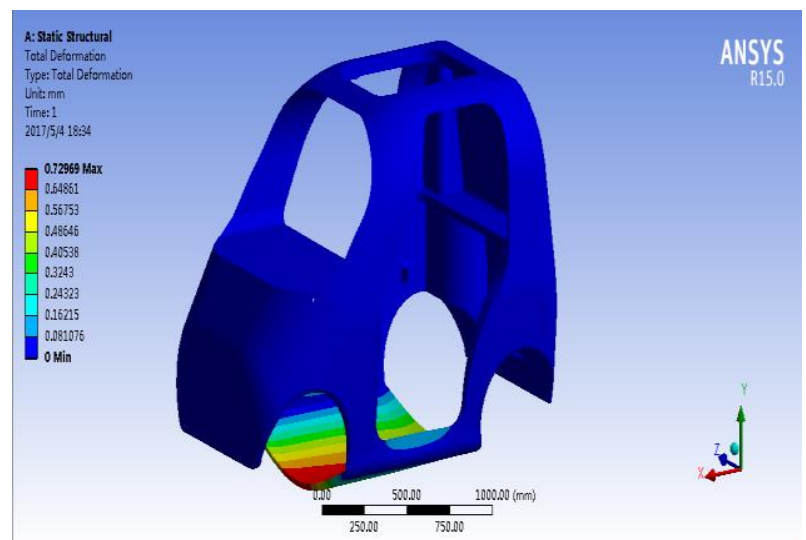

(a)

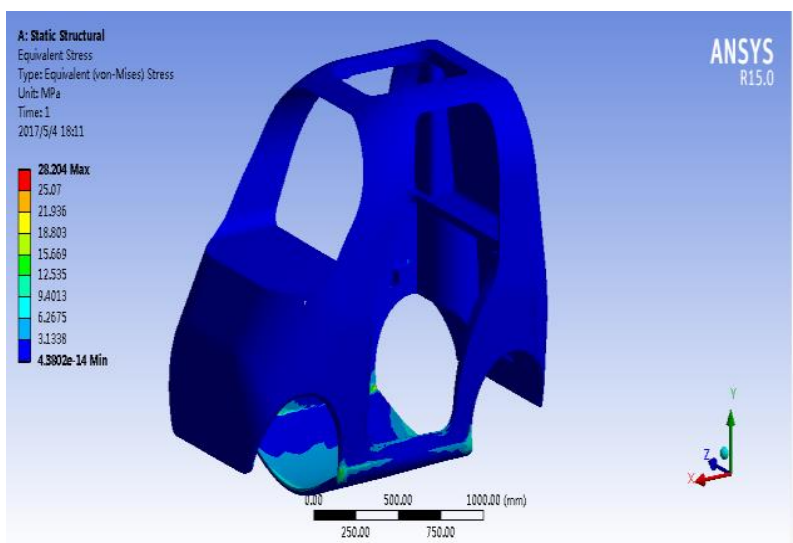

(b)

Figure 4. (a) Bending strain (b) Bending stress

According to the calculation results of the deformation diagram, the maximum stress value of the body under bending condition is $28.204 \mathrm{Mpa}$. The result is lower than the yield strength of aluminum alloy, and meets the requirements of strength. And through the body deformation diagram, we could get that the maximum deformation occurs at the front of the body floor is $0.73 \mathrm{~mm}$ and bending stiffness is $5479 \mathrm{~N} / \mathrm{mm}$.

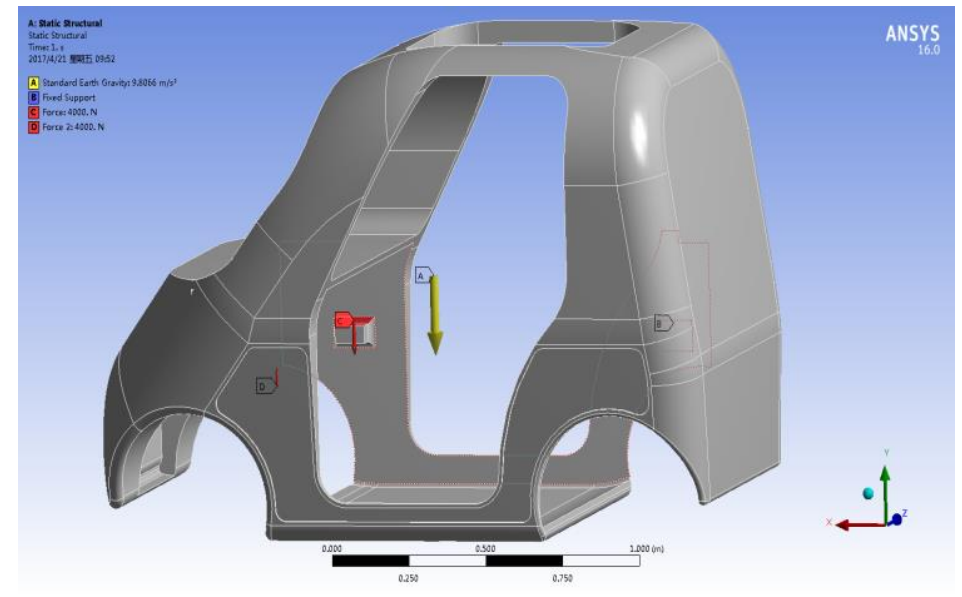

Figure 5. Torsion load restraint

The loading of the car body in torsion is shown in Fig. 5. The translational freedom of the $\mathrm{X}$ and $\mathrm{Y}$ directions is restrained at the rear support seat, and the $\mathrm{Y}$ axis load concentrated force $2000 \mathrm{~N}$ with the same magnitude and opposite direction is applied to the front support seat.

Then the statics of the car body torsion condition are calculated by using ANSYS, and the results of the deformation are shown in figures 6(a) and 6(b). According to the figure that the maximum stress value of torsion car body is $36.67 \mathrm{MPa}$. It occurs at the right sill and below the yield strength of the aluminum alloy. So the results meet the strength requirement. 


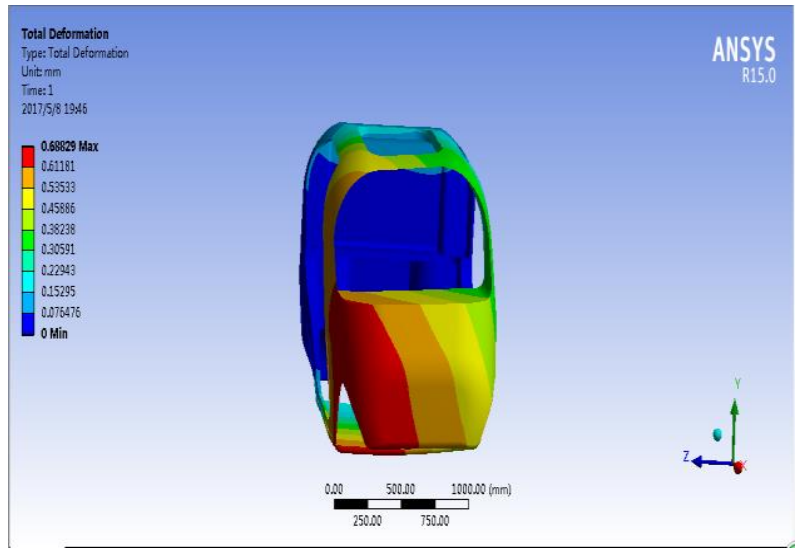

(a)

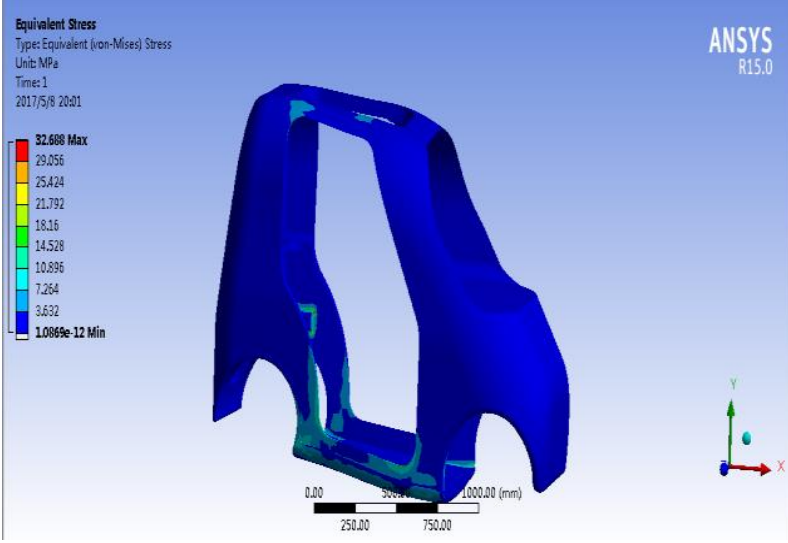

(b)

Figure 6. (a) Torsion strain (b) Torsion stress

In summary, the designed car body meets the requirements of the frontal strength and stiffness of the car under bending conditions. It guarantees the safety and reliability of the pure electric car.

\section{Dynamic Analysis}

Table 3 lists that the frequencies and mode of car body. Figure 7 are the first six modes of car body. The dynamic performance of the object depends mainly on the low order vibration modes in this paper. The main concern in car body design is the minimum number of frequencies that cause the body to resonate. Therefore, the first 6 modes are extracted in modal analysis.

Table 3 The frequencies and mode of the car body

\begin{tabular}{cccc}
\hline Mode & Frequency $(\mathrm{Hz})$ & Max deformation $(\mathrm{mm})$ & \begin{tabular}{c} 
Vibration type \\
\hline 1
\end{tabular} \\
20.467 & 2.00 & $\begin{array}{c}\text { Front left and right swings } \\
\text { of car body }\end{array}$ \\
\hline 2 & 21.7 & 1.76 & $\begin{array}{c}\text { The front of the car } \\
\text { swings up and down }\end{array}$ \\
\hline 3 & 51.493 & 2.08 & First order torsion \\
\hline 4 & 59.893 & 6.56 & First order bending \\
\hline 5 & 68.516 & 3.54 & $\begin{array}{c}\text { The bottom of the car } \\
\text { swings left and right }\end{array}$ \\
\hline 6 & 71.141 & 1.83 & Car body swing \\
\hline
\end{tabular}

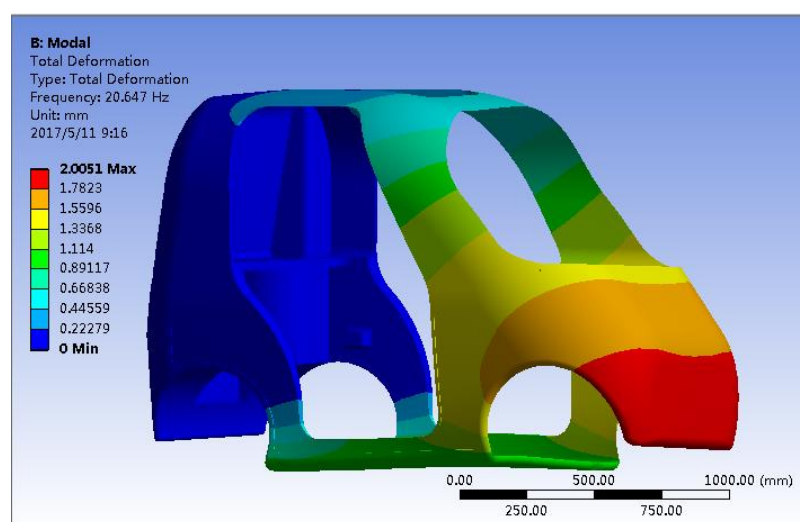

(a) $1 \mathrm{st}$

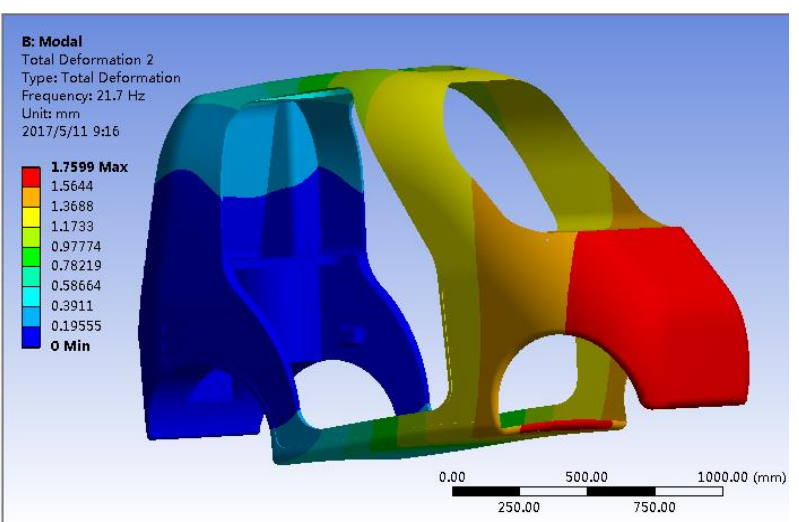

(b)2nd 


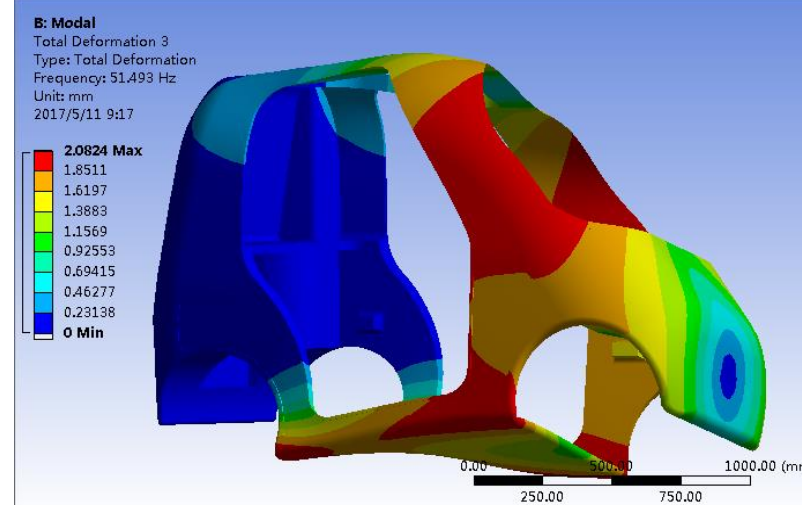

(c) 3rd

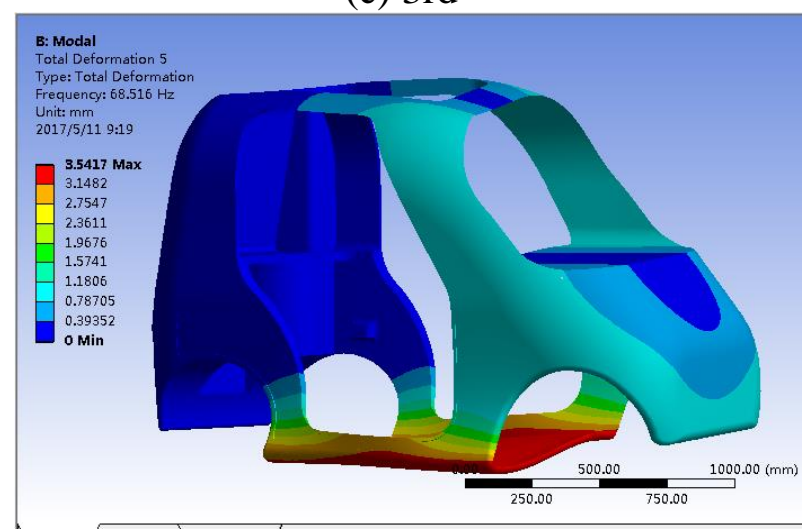

(e) 5 th

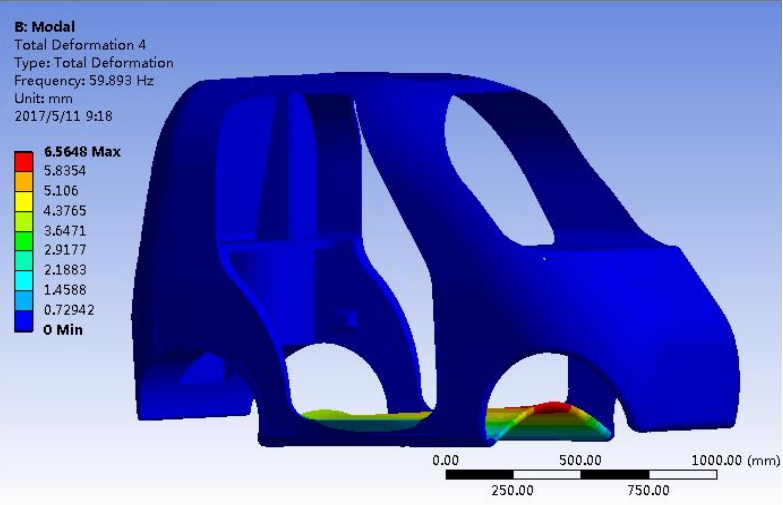

(d) 4th

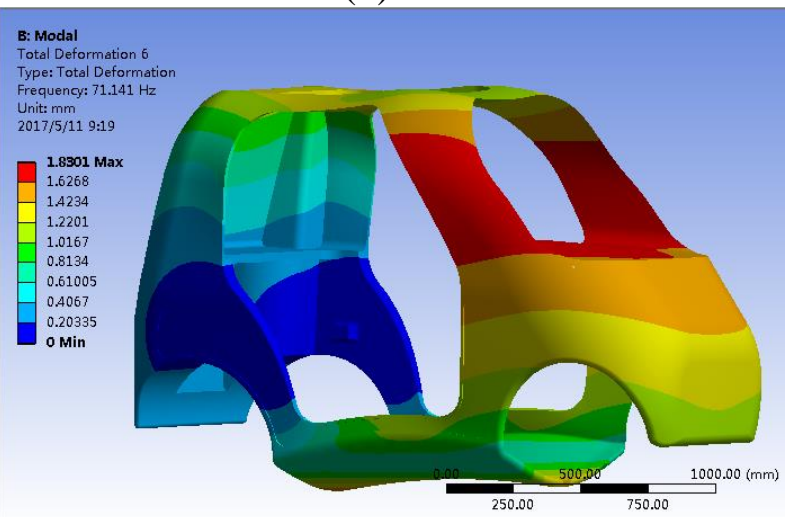

(f) 6th

Figure 7. The first six modes of car body.

The excitations for pure electric vehicles come from a variety of factors. Road excitation is determined by the condition of the road surface. On urban roads and highways have good road condition, the motivation is generally $1 \sim 3 \mathrm{~Hz}$, which is negligible. The speed is $50-80 \mathrm{~km} / \mathrm{h}$ on the city road or the speed is $80-120 \mathrm{~km} / \mathrm{h}$ on the highway. The excitation caused by the transmission shaft is large, and the vibration frequency is above $40 \mathrm{~Hz}$. In general, the first order frequency of the car body should be in the range of $20 \sim 30 \mathrm{~Hz}$. The frequency of car body designed is $20.467 \mathrm{~Hz}$ in this paper, which is located in the normal range.

It is the ability of body structure to resist torsion and bending deformation in the first order torsion and first order bending. The velocity response near frequency $30 \mathrm{~Hz}-40 \mathrm{~Hz}$ is greater in car body design. This is caused because of the resonance by excitation frequency and first order bending and first order torsion of car body. Therefore, the design requirement of the body is that the first torsion frequency is greater than $30 \mathrm{~Hz}$, and the first bending frequency is greater than $40 \mathrm{~Hz}$. According to the results of modal analysis, it can be concluded that the design of the body meets the requirements of modal analysis.

\section{Conclusion}

According to the difference of pure electric vehicle and traditional fuel vehicles, taking into account the design of compact and lightweight body structure design in this paper. The author used the finite element analysis method of mechanics based on ANSYS software. The car body structure design and mechanical analysis is carried out to ensure the structural mechanical characteristics of the car body 


\section{Acknowledgements}

This study is sustained by Fujian Nature Project No. 2016J01039 and 2015J01228, Xiamen City Project No. $3502 Z 20173037$

\section{References}

[1] Deb A., Mahendrakumar M.S., Chavan C. (2004), Design of aluminium-based vehicle platform for front impact safety. International Journal of Impact Engineering. 30, pp.1055-1079.

[2] Wang L.X., Zhao T.F., Cao J.B. (2014), Design of Body Structure for New Type Lightweight Electric Vehicle. Key Engineering Materials. 620, pp. 335-340.

[3] Lei Z.B., Xiao L.H., (2016), Overall topological optimization design of Crashworthiness of pure electric vehicle body. Journal of Automotive Engineering. 1. pp. 15-21.

[4] Botkin M. E., (2008), Structual optimization of automotive component based on parametric solid modeling. Engineering with computers. 18, pp. 109-115.

[5] Nagesh B., Richard S., Reduction of Passenger Car Noise Using Computational Analysis. SAE paper. 851092.

[6] Zhu C., Chiu Y.J., Pan Q., (2014), The Study of Localization Phenomenon of Three Automobiles. Applied Mechanics and Materials. 574, pp. 243-246. 